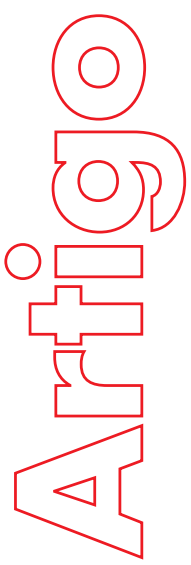

Revista

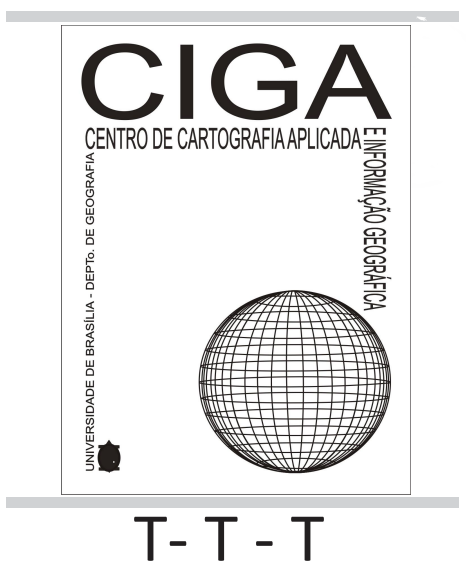

Revista Eletrônica: Tempo - Técnica - Território, V.11, N.2 (2020), 01:20 ISSN: 2177-4366

\section{ANÁLISE DAS RELAÇÕES ETNICO-RACIAIS E'DO BRASILAFRICANO NO LIVRO DIDATICO DE GEOGRAFIA “EXPEDICÓES GEOGRÁFICAS $7^{\circ}$ AÑO"}

\author{
Ramon da Silva R. Almeida
}

p. $01-20$

Como citar este artigo:

Almeida, R. S. R.

ANÁLISE DAS RELAÇÕES ÉTNICO-RACIAIS E DO BRASILAFRICANO

NO LIVRO DIDÁTICO DE GEOGRAFIA “EXPEDIÇÕES GEOGRÁFICAS 70

ANO" Revista Eletrônica: Tempo - Técnica - Território, v.10, n.2

(2020),p.01:20 ISSN: 2177-4366.

Disponível em: http://periodicos.unb.br/index.php/ciga/

Este obra está licenciado com uma Licença

Creative Commons Atribuição - Não Comercial 4.0 Internacional. 


\title{
ANÁLISE DAS RELAÇÕES ÉTNICO-RACIAIS E DO BRASIL AFRICANO NO LIVRO DIDÁTICO DE GEOGRAFIA “EXPEDIÇÕES GEOGRÁFICAS 7 ANO”
}

\author{
Ramon da Silva R. Almeida \\ Graduando em Geografia pela Universidade de Brasília, Disciplina GEOAFRO - $1^{\circ}$ \\ Semestre 2020. E-mail: ramoniitto@gmail.com
}

RESUMO: Este trabalho se propõe a analisar o livro Expedições Geográficas, destinado a estudantes do $7^{\circ}$ ano do Ensino Fundamental. É importante levar em conta que os livros didáticos são instrumentos de papel relevante no processo de ensino-aprendizagem e, portanto, carecem de atenção, cuidado e criticidade em sua formulação. Independente da didática e ensinagem dos professores, o livro didático é um importante aliado e pode direcionar a condução dos conteúdos trabalhados e das reflexões colocadas em discussão nas salas de aula e podem ser as únicas fontes de consulta, leitura e estudo dos estudantes. Sendo assim, e como objetivo deste artigo, entendemos que as questões étnico-raciais e o Brasil Africano são erroneamente tratadas nos livros didáticos, pela difundida presença do mito da democracia racial no imaginário social brasileiro, além da reprodução hegemônica do pensamento eurocêntrico e branco que permeia as ciências e as instituições e logo implicam na confecção e elaboração dos materiais didáticos e na formação dos docentes e, consequentemente, na abordagem do tema em sala de aula. Com isso, aponta-se para a necessidade de uma abordagem transversal do "Brasil Africano" no livro como indica a Lei 10.639/2003 e propor a desmitificação do exotismo do tema apenas ao que se refere à diversidade cultural e à miscigenação.

Palavras-chave: Livro diático; Geografia Afrobrasileira; Ensino de Geografia; Lei $10.639 / 2003$

ABSTRACT:This work proposes an analysis of the book Geographical Expeditions, destined for students of the 7th year of Elementary School. It is important to take into account that textbooks are instruments of relevant role in the teaching-learning process and, therefore, they lack attention, care and criticality in their offer. Regardless of the didactics and teaching of the teachers, the textbook is an important ally and can direct the conduct of the contents worked and the reflections put into discussion in the classrooms 
and can be the only sources of consultation, reading and study of the students. Therefore, and as the objective of this article, we understand that ethnic-racial issues and African Brazil are mistakenly dealt with in textbooks, due to the widespread presence of the myth of racial democracy in the Brazilian social imagination, in addition to the hegemonic reproduction of Eurocentric and white thought that it permeates the sciences and institutions and the logo implies in the preparation and preparation of teaching materials and in the training of teachers and, consequently, in addressing the theme in the classroom. With that, it points to the need for a transversal approach of "African Brazil” in the book as indicated by Law 10.639 / 2003 and to propose the demystification of the exoticism of the theme only with regard to cultural diversity and miscegenation.

Keywords: Textbook; Afro-brazilian Geography; Geography teaching; Law 10.639/2003.

\section{INTRODUÇÃO}

As escolas são instituições que visam colaborar e construir junto com indivíduos o conhecimento sobre o mundo em um processo contínuo de humanização e sociabilização (Ratts et al, 2006), portanto é uma instituição com função social de formação crítica e emancipadora e, também um lugar de acolhimento e de promoção do respeito e da diversidade.

Contudo, a escola é um microcosmo da sociedade e logo produz e reproduz vários ideários e representações contidas no mundo fora dos muros escolares. Dessa forma, o racismo e discriminações se fazem presentes na comunidade escolar, desde as relações interpessoais até a forma como o conhecimento é ensinado (Ratts et al, 2006).

Apesar da conquista de políticas públicas e da implementação de leis como a Lei 10.639/2003 que torna obrigatório o ensino da história e cultura afro-brasileira na educação básica, persistem entraves que dificultam o ensino do continente e da matriz africana nas escolas pela imposição do conhecimento eurocêntrico, branco e colonial que ainda persiste em todas as brechas de nossa sociedade (Rocha, 2011). Assim, os 
conteúdos e currículos escolares não privilegiam a abordagem da questão étnico-racial dentro das salas de aula e, quando o fazem é de forma velada ou superficial.

De forma sistêmica a reprodução desses entraves dar-se muitas vezes pela formação falha dos educadores nos cursos universitários e a inexistência da formação continuada voltada ao estudo das relações étnico-raciais. Os profissionais da educação não estão preparados para tratar da questão racial em sala de aula, tanto quanto aos aspectos pedagógicos quanto nas relações sociais cotidianas.

E unidos a estas problemáticas temos os livros didáticos que pouco contemplam a diversidade da sociedade e do ambiente escolar e muitas vezes trata a questão étnicoracial de forma inadequada (Ratts et al, 2006). A partir disso, será analisado de forma qualitativa o livro didático de geografia Expedições Geográficas do ensino fundamental do $7^{\circ}$ ano da Editora Moderna a fim de identificar como o livro aborda os conteúdos referentes às questões étnico-raciais e a matriza africana no Brasil contemporâneo.

1. FAÇA A FICHA TÉCNICA DO LIVRO (AUTOR, EDITORA, ANO DE PUBLICAÇÃO, EDIÇÃO etc.) E DESCREVA RESUMIDAMENTE COMO SE APRESENTA A ESTRUTURA DO LIVRO DIDÁTICO (UNIDADES, CAPÍTULO, ITENS, ETC).

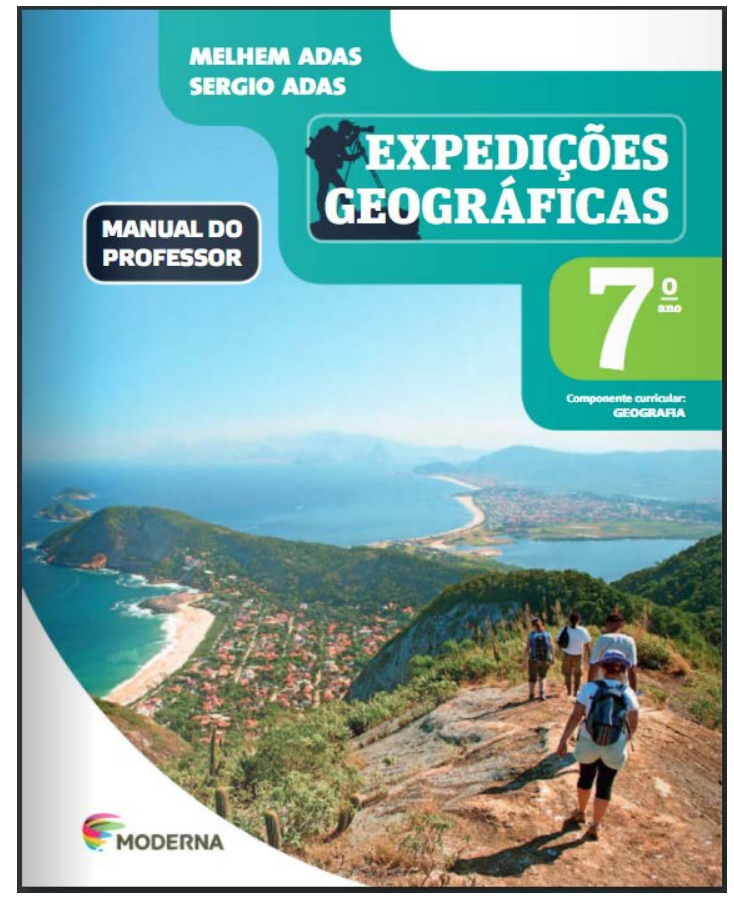

Figura 1. Capa do Livro Didático Expedições Geográficas $7^{\circ}$ ano Fonte: Editora Moderna, 2018

Ficha Técnica 


\begin{tabular}{|l|}
\hline Título: Expedições Geográficas - $7^{0}$ ano \\
\hline Componente Curricular: Geografia \\
\hline Autor/Autora(es/as): Melhem Adas e Sérgio Adas \\
\hline Editora: Editora Moderna \\
\hline Ano de publicação: 2018 \\
\hline Edição: $3^{\text {a }}$ edição \\
\hline
\end{tabular}

O livro de geografia Expedições Geográficas do $7^{\circ}$ ano é organizado em 8 unidades, nomeadas pela publicação por Expedições. Cada unidade ou expedição é composta por 4 capítulos ou também chamados de Percursos, sendo assim são totalizados 32 capítulos ou percursos no livro.

As unidades e os capítulos do livro possuem em seu conteúdo textual a mescla de gráficos, tabelas, mapas e infográficos. Além disso, tem-se ao longo do livro textos de revistas e jornais chamados de Estações e tratam de temas transversais que complementam ao que está sendo tratado nas unidades e capítulos. Logo, as Estações são divididas em 4: Estação Socioambiental, Cidadania, História e Ciências.

A figura abaixo (figura 1) apresenta a divisão das quatro primeiras unidades da obra e seus respectivos capítulos elencados sobre: o território brasileiro; a população brasileira; o processo de industrialização, consumo e as redes do espaço geográfico e o estudo da divisão regional do Brasil.

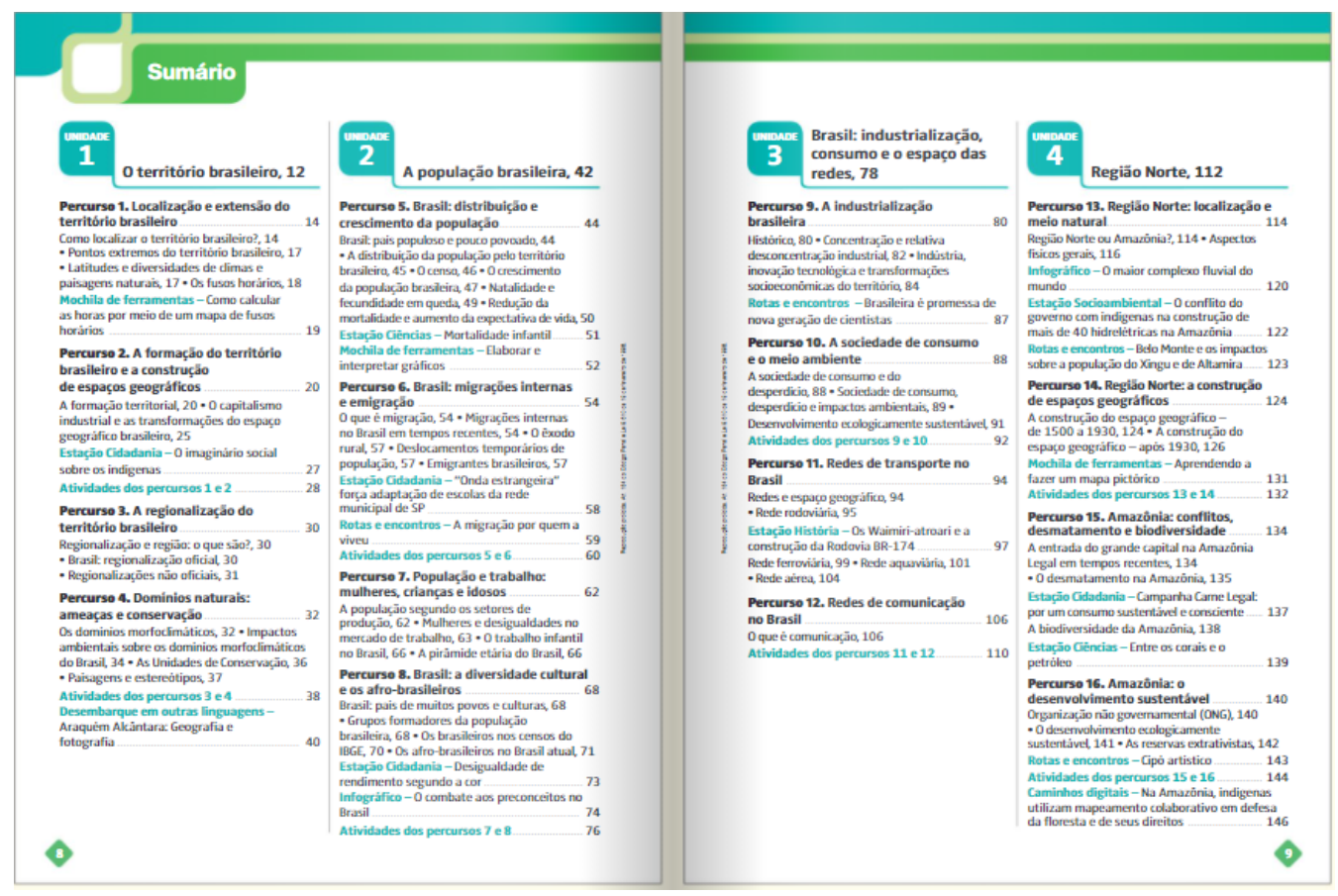


Figura 2. Sumário do livro didático Expedições Geográficas Fonte: Editora Moderna, 2018

Na unidade 1 e seus capítulos é tratado sobre: a formação dos territórios e espaços geográficos brasileiros; o processo de formação das fronteiras e limites e a regionalização política-administrativa do território. Já na unidade 2 é abordado a temática da formação da população brasileira, sua distribuição pelo território e territorialidades e alguns conceitos chaves como população absoluta e relativa, densidade demográfica, migração, censo e diversidade demográfica e cultural.

Na unidade 3 são estudadas o processo de industrialização brasileira e sua relação com o consumo, propaganda, o desperdício e as consequências ambientais dessa dinâmica. Ainda na unidade 3 é estudado as técnicas e os fluxos no espaço geográfico como formas de integração do território com a densidade das redes de transporte e de comunicação.

Depois de 3 unidades tratando sobre aspectos gerais de formação e dinâmica do território e de sua população, as unidades seguintes 4,5,6,7 e 8 irão abordar, respectivamente, uma região do Brasil: Norte, Nordeste, Sudeste, Sul e Centro Oeste e as características naturais, socioeconômicas e histórico de ocupação humana de cada uma (ver figura 3).

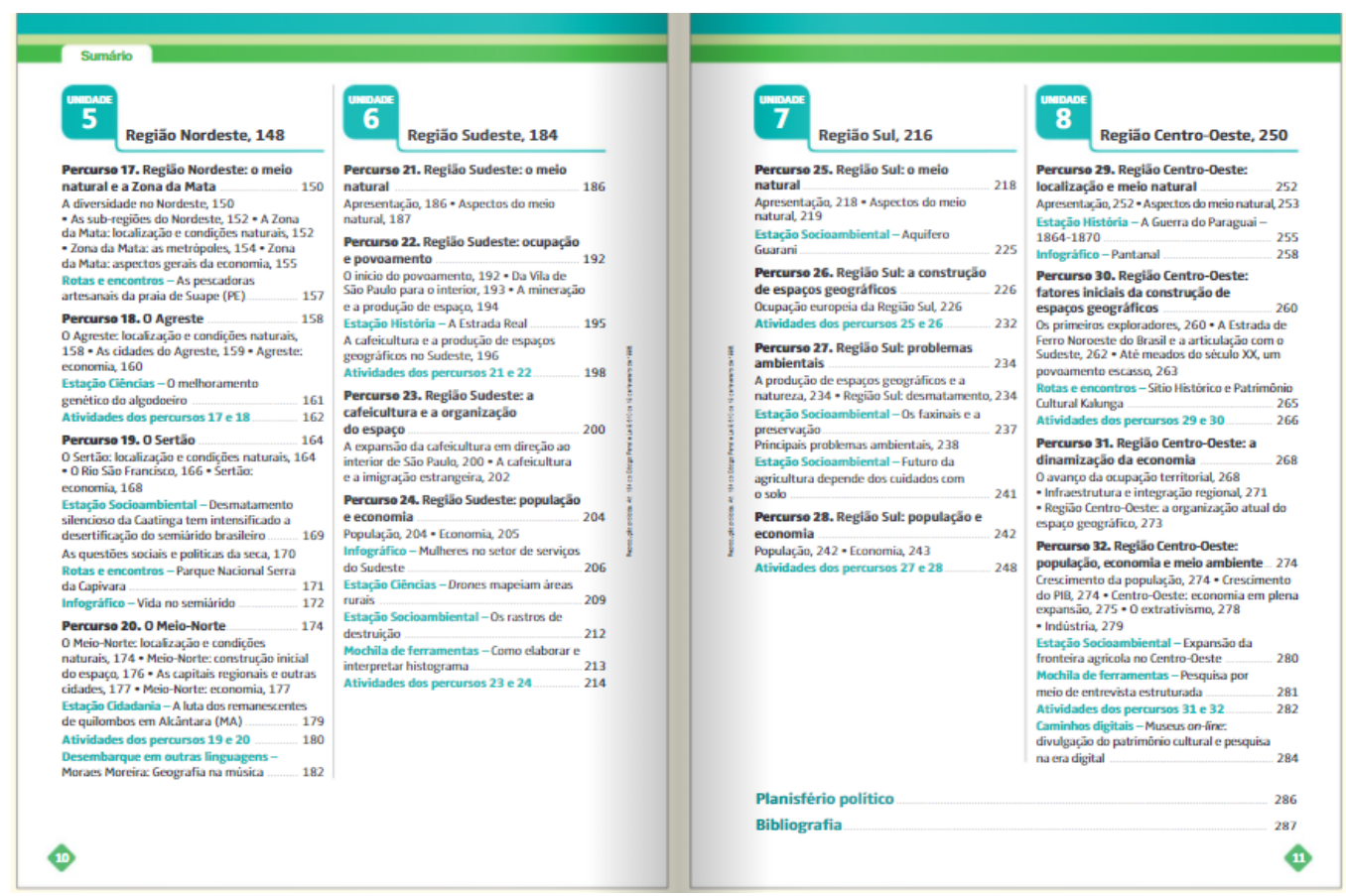

Figura 3. Sumário do livro didático Expedições Geográficas Fonte: Editora Moderna, 2018 


\section{2. É POSSÍVEL DETECTAR A CONCEPÇÃO DE GEOGRAFIA QUE O LIVRO EXPLICITA? POR EXEMPLO, CRÍTICA, CONSERVADORA, DESCRITIVA, DENTRE OUTRAS.}

A partir dos conteúdos analisados, a publicação tende a uma concepção da Geografia Crítica. Em seus escritos nota-se uma tentativa de apresentar o reflexo das forças e contradições do sistema capitalista no espaço geográfico e na organização socioespacial do território, como por exemplo na explicação sobre a formação territorial do Brasil a partir da dinâmica do colonialismo ou mesmo do processo de industrialização e as transformações no espaço e na população.

Além disso, os textos trazidos pelo livro propõem-se a questionamentos sociais sobre os cenários reproduzidos pelo sistema capitalista e suas implicações na vida dos cidadãos. Desse modo segue-se a tendência da Geografia Crítica e sua correlação com a Geografia Escolar na espera que a partir dos conteúdos e da abordagem trazida possa formar estudantes cidadãos e críticos.

\section{QUAL O CONCEITO DE ESPAÇO GEOGRÁFICO ADOTADO PELO LIVRO? ELE ESTA EXPLICÍTO?}

Tomando por base a Geografia Crítica que orienta os escritos do livro podemos inferir que o conceito de espaço geográfico adotado é o miltoniano que tem por base o espaço produzido ou construído pelas forças sociais e técnicas, sendo esta última considerada na perspectiva como um conjunto de meios que os seres humanos dispõem num dado momento e dentro de uma organização social, econômica e política para modificar a natureza (Santos, 1988).

Desse modo, os meios de produção se efetivam por intermédio das técnicas, sejam elas produtivas, sociais ou políticas, mas que não são originárias de um só momento histórico. Assim o espaço geográfico se apresenta como um produto histórico sociocultural que expressa a organização das sociedades e um conjunto indissociável dos objetos geográficos, naturais e sociais e os sujeitos (Santos, 1988).

\section{EXISTE ALGUM CAPÍTULO QUE ABORDE AS QUESTÕES ÉTNICO- RACIAIS NO BRASIL? COMO ELE SE APRESENTA?}

As questões étnico-raciais são abordadas na primeira unidade e no capítulo 2 do livro quando se vai trabalhar com os aspectos da formação territorial, a construção dos 
espaços geográficos e papel dos grupos humanos nesse processo desde o início da colonização, dos ciclos econômicos do açúcar, ouro, café, entre outros, até o capitalismo industrial e suas implicações na sociedade.

Os povos indígenas são citados brevemente como parte desse processo de formação e ao final do capítulo tem-se o boxe Estação Cidadania com um texto que trata do imaginário social sobre os indígenas e do extermínio das culturas provocado pelos europeus no continente e de como isso influenciou na construção dos preconceitos e discriminações sofridos e as implicações atuais no processo político da demarcação dos territórios desses povos.

No que tange à população africana e afro-brasileira não ocorre citação e sim um apagamento quando o livro se refere à formação territorial do Brasil. Nem mesmo a partir da ótica histórica do sistema escravista são citadas as influências africanas na dinâmica socioespacial brasileira. Ao longo do capítulo fala-se sobre os ciclos econômicos como “motores” da construção do espaço geográfico, mas é apagado os africanos escravizados que foram o eixo de sustentação desse sistema e da própria consolidação do território brasileiro.

Já na próxima unidade (unidade 2) é aprofundado sobre os aspectos demográficos do território e os grupos que compõem a população brasileira. Em específico, como mostrado na figura 4, o capítulo 8 tem como nome: "Brasil: a diversidade cultural e os afro-brasileiros” e tem por objetivo trabalhar a pluralidade brasileira a partir da perspectiva da miscigenação dos vários povos no território: indígenas, africanos, europeus e asiáticos. Cada grupo populacional é tratado dentro de tópicos específicos com mapas e imagens representativas ao longo do capítulo. 


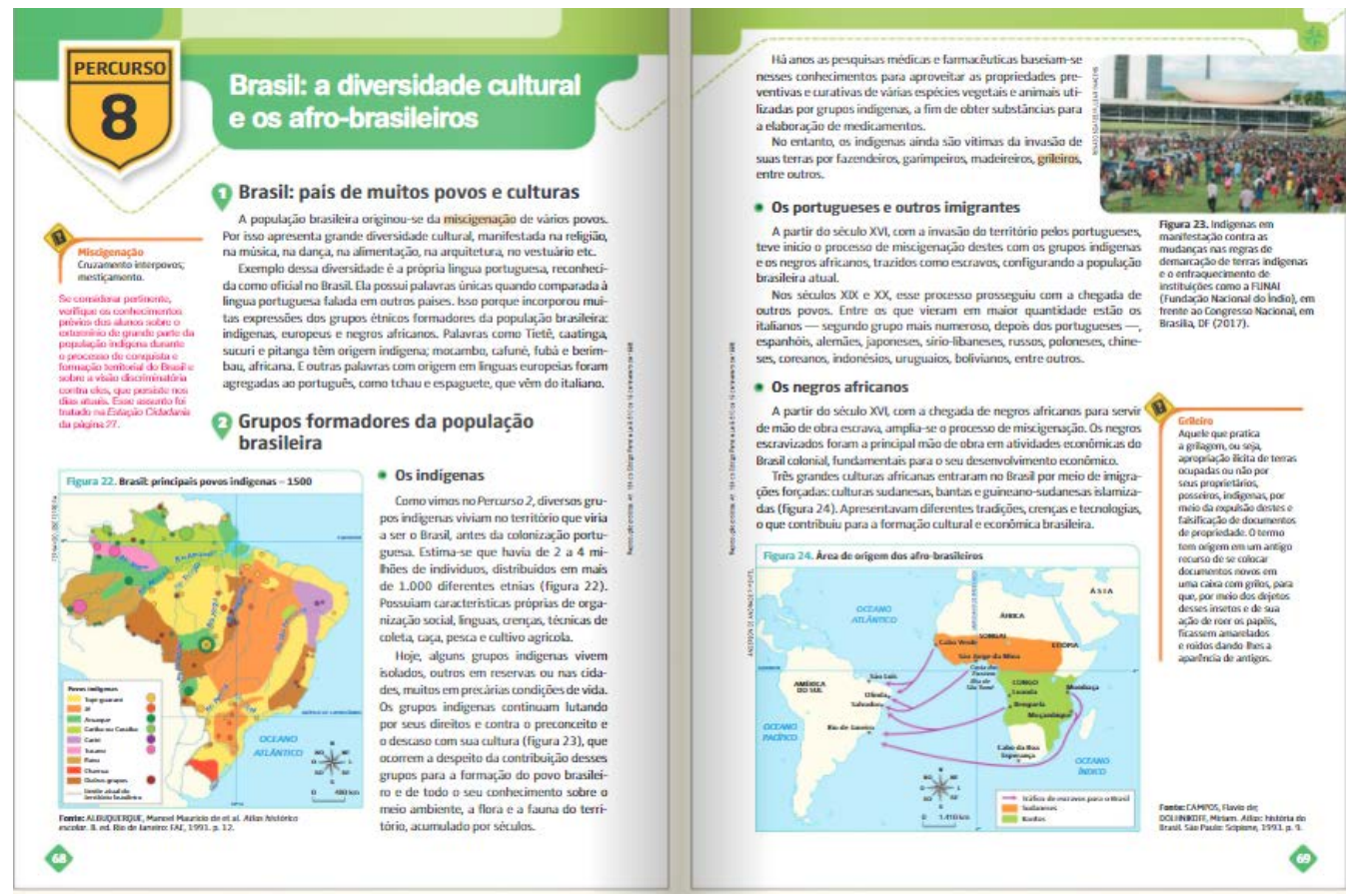

Figura 4. Capítulo 8 - Brasil: a diversidade cultural e os afro-brasileiros no livro didático Expedições Geográficas $7^{\circ}$ ano Fonte: Editora Moderna, 2018.

De forma breve e resumida o tópico sobre os povos indígenas cita somente a diversidade de etnias que habitavam o Brasil e os problemas da demarcação de terras e os conflitos com grileiros e posseiros.

No que se refere à população africana e afro-brasileira, o capítulo 8 trata o assunto também de forma breve e superficial, é falado sobre o tráfico de pessoas africanas e o sistema escravista colonial no Brasil, no entanto o tema é trabalhado sem contextualização e sem relacionar com os conteúdos já citados na unidade anterior como por exemplo o processo de formação do territorial.

De forma geral podemos apontar que este capítulo é o único do livro que trata sobre as questões étnico-raciais quanto à população africana e afro-brasileira. Além do tema sobre escravidão são trabalhados conteúdos atuais sobre os afro-brasileiros como a questão quilombola, as desigualdades socioeconômicas, o racismo e os movimentos sociais negros e suas conquistas políticas como as ações afirmativas.

Contudo, é importante pontuar que a abordagem da temática das relações étnicoraciais no livro é extremamente rasa e seu conteúdo pode ser visto como mero informe, pois não existe uma contextualização histórica, o trabalho com categorias e conceitos geográficos e uma sequência didática lógica entre os mais variados temas abordados em 
todo livro. Logo, os temas são trazidos sem levantar a criticidade proposta pela corrente geográfica escolhida que embasa a publicação.

\section{EXISTEM EXPLICAÇÕES SOBRE O SISTEMA ESCRAVISTA VIGENTE QUASE QUATRO SÉCULOS NO BRASIL COLONIAL/IMPERIAL? COMO ELE É TRATADO?}

Não existe em nenhuma unidade ou capítulo do livro uma explicação sobre o sistema escravista colonial/imperial, mesmo com suas implicações na dinâmica de transformação do espaço brasileiro. Entretanto, o tema é abordado breve e pontualmente no capítulo que trata sobre a diversidade cultural da população brasileira no âmbito do grupo dos africanos e afro-brasileiros e ainda assim é reforçando a existência desses povos em condições brutais de existência e como mera mão de obra nas atividades econômicas do Brasil.

\section{O LIVRO APRESENTA IMAGENS DE CONTEXTOS AFROBRASILEIROS DE MANEIRA ESTEREOTIPADA?}

As imagens são importantes recursos didáticos no ensino da geografia e possuem grande propriedade comunicativa e se for bem usada, pode trazer avanços significativos no processo de ensino-aprendizagem (Marcelino, 2020).

No livro são poucas as imagens de afro-brasileiros e as poucas representações são de mulheres negras em situações cotidianas (ver figura 5) ou exercendo profissões, como médicas e cientistas (ver figura 6 e 7).

Porém, na contramão disso o livro apresenta duas figuras que representam o sistema escravocrata. A partir disso podemos refletir o quanto a representação excessiva destas imagens nos diversos materiais didáticos reforça estereótipos racistas e o imaginário social das crianças e adolescentes mesmo que a intencionalidade seja a memória da história.

Desse modo, mostra-se a necessidade de ampliar nos livros as imagens que mostrem a diversidade dos povos africanos e afro-brasileiros, a sua heterogeneidade enquanto grupo social e dinâmico marcado pela diversidade cultural, religiosa, política etc. e não condicionados à papéis sociais subalternos e a condições de pobreza, miséria e desastres. 


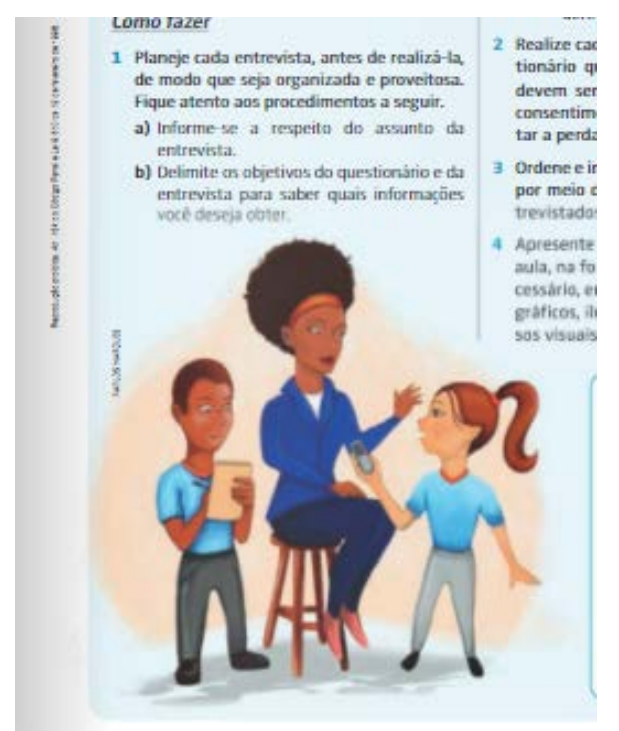

Figura 5. Desenho de uma mulher sendo entrevistada no livro Expedições Geográficas $7^{\circ}$ ano Fonte: Editora Moderna, 2018.

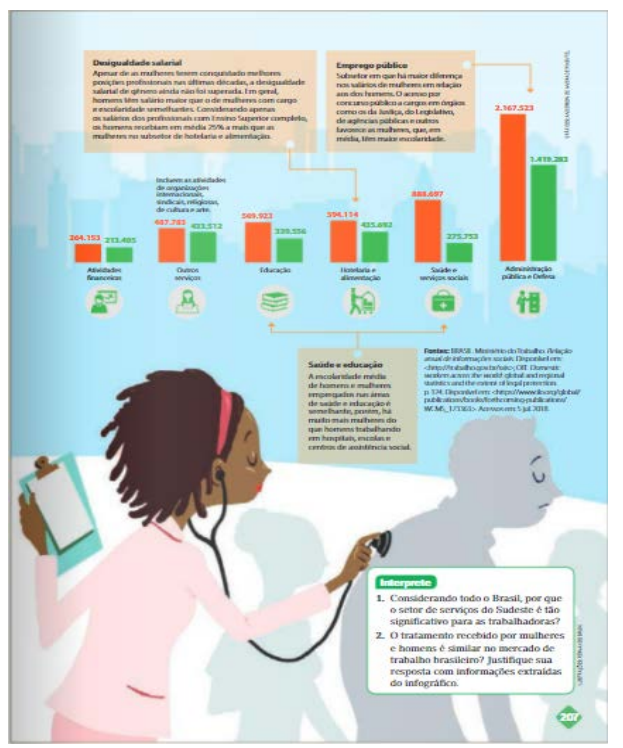

Figura 6. Desenho de uma mulher negra como médica no livro didático Expedições Geográfica $7^{\circ}$ ano Fonte: Editora Moderna, 2018. 


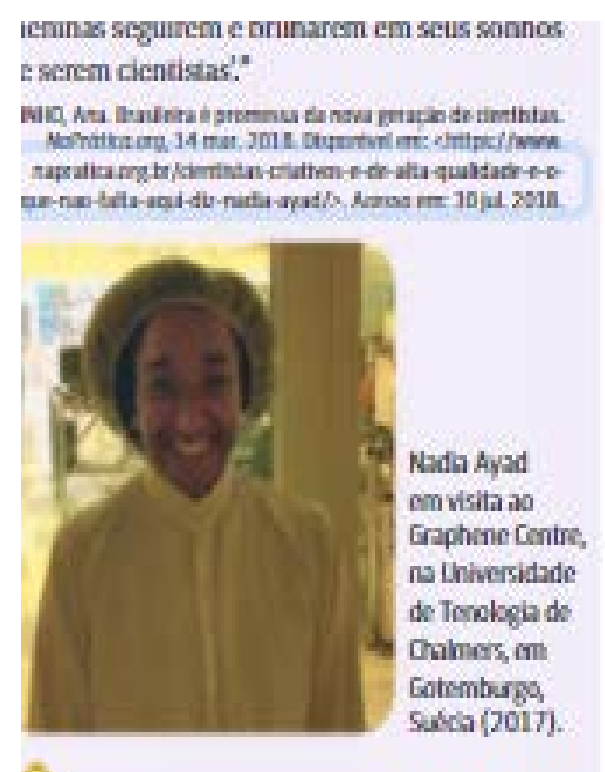

Figura 7. Foto de uma cientista no livro didático Expedições Geográficas $7^{\circ}$ ano Fonte: Editora Moderna, 2018.

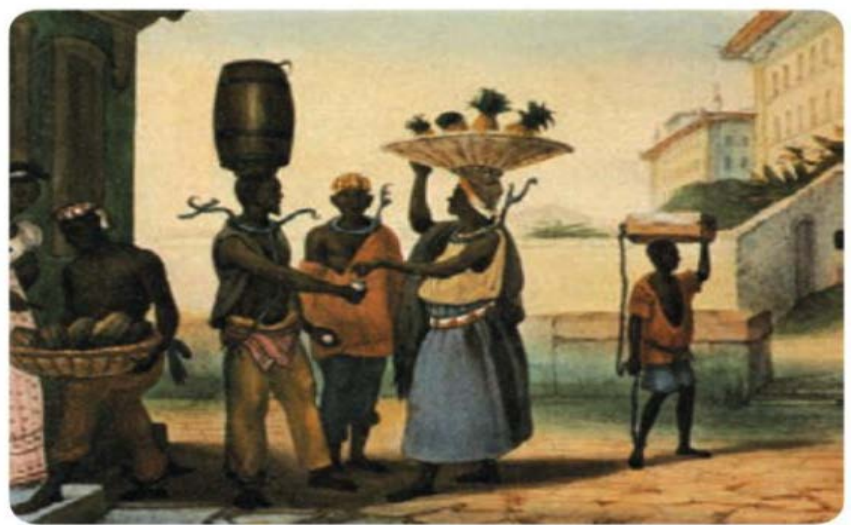

Figura 8. Litografia do artista Debret sobre a escravidão no livro didático Expedições Geográficas $7^{\circ}$ ano Fonte: Editora Moderna, 2018.

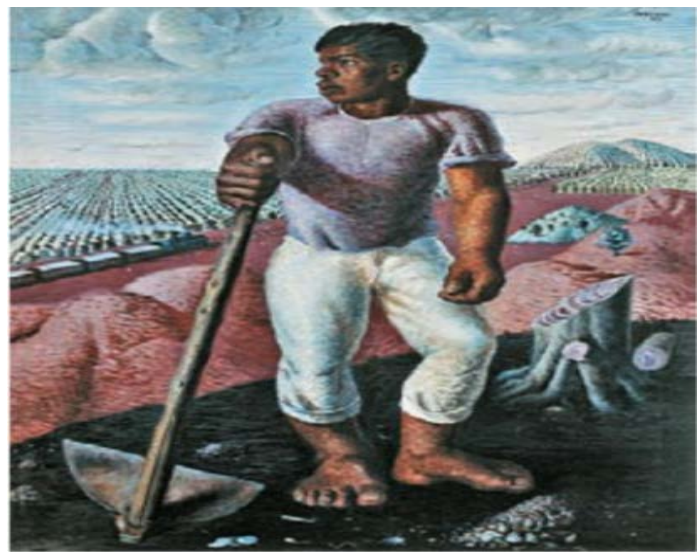

Figura 9. Pintura de Cândido Portinari de um homem escravizado na lavoura de café no livro didático Expedições Geográficas $7^{\circ}$ ano Fonte: Editora Moderna, 2018. 


\section{EXISTEM REFERÊNCIAS (TABELAS, MAPAS, TEXTOS, ETC.) SOBRE A DIVISÃO DA SOCIEDADE BRASILEIRA POR GRUPO ÉTNICO E/OU “COR”? SE HOUVER ELA É SEGUIDA DE UMA REFLEXÃO CRÍTICA?}

Ao referir sobre a população brasileira apresenta-se um gráfico elaborado pelo IBGE com a distribuição da população segundo a cor da pele (ver figura 7), acompanhado ao gráfico vem um texto que explica sobre o direito à autodeclaração da cor pelas pessoas e a importância da coleta e existência dos dados censitários.

Nisso, é pontuado o quanto esses dados dão respaldo à formulação e avaliação de políticas públicas e, segundo o livro: “contribuem para melhorar a vida dos menos favorecidos” (Adas e Adas, 2018) no caso pessoas pretas, pardas e indígenas.

Entretanto, assim como no restante do livro e não é feito uma explicação teórica e histórica sobre a maioria da população parda e o processo de embranquecimento promovido pelo sistema colonial dominante, nem mesmo quando a temática é tratada no capítulo sobre o fluxo migratório no Brasil.

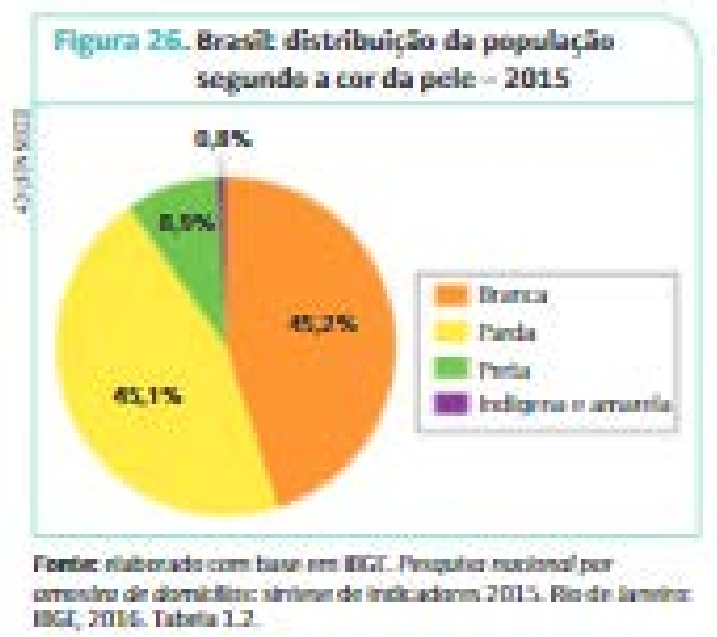

Figura 7. Gráfico da distribuição da população brasileira segundo a cor da pele no livro didático Expedições Geográficas $7^{\circ}$ ano Fonte: Editora Moderna, 2018.

\section{NO LIVRO HÁ REFERÊNCIAS SOBRE A SITUAÇÃO SOCIAL, ECONÔMICA E POLÍTICA DOS AFROBRASILEIROS NO PAÍS?}

Ao respaldar os assuntos contemporâneos sobre a situação socioeconômica e política dos afro-brasileiros o assunto é resumido novamente apenas por um único capítulo do livro com uso de gráficos, mapas, infográficos para embasar as informações e dados fornecidas ao longo dos textos. 
No boxe Estação Cidadania é tratado sobre as desigualdades econômicas no Brasil segundo a cor da pele ao longo dos anos de 2005 a 2015. No gráfico abaixo (figura 10) temos as informações que dentre os 1\% dos mais ricos do país em 2015, apenas 17,8\%\% são de pessoas pretas ou pardas enquanto a porcentagem de pessoas brancas detentoras dessa riqueza chega em $79,7 \%$.

Contudo, as informações e os números são apenas dados, sem nenhuma explicação teórica sobre as origens dessa desigualdade e suas implicações na vida cotidiana da população afro-brasileira. Em uma perspectiva positiva o livro propõe perguntas para que os estudantes pensem, respondam e alimentem o debate sobre o assunto.

Contudo, salienta-se que a proposta pedagogicamente pode ser interessante e válida, mas é importante que sejam dados conhecimentos prévios para os estudantes fomentarem a reflexão e evitar o fortalecimento das práticas do racismo, de modo que essas informações excessivas sem contexto possam contribuir na reprodução dos estereótipos no qual pessoas pretas estão fadadas a uma condição social de mazela (Marcelino, 2020).

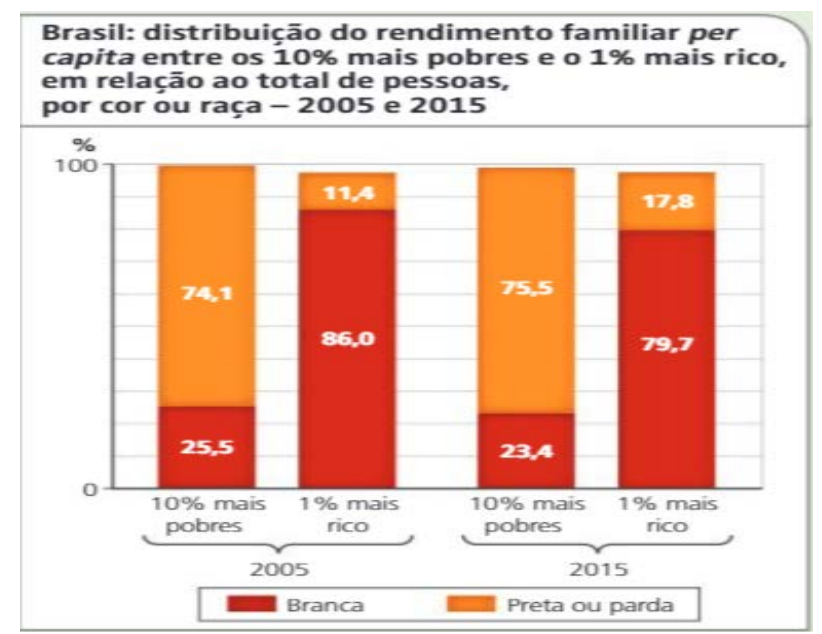

Figura 10. Gráfico do rendimento familiar per capita por cor no Brasil no livro didático Expedições Geográficas $7^{\circ}$ ano Fonte: Editora Moderna, 2018.

Ainda no mesmo capítulo e no próximo que estuda a Região Nordeste, especificadamente, no subtópico do Meio Norte o livro traz à tona a discussão sobre os afro-brasileiros e as comunidades "remanescentes” de quilombos.

O assunto é abordado com o uso da linguagem cartográfica (ver figura 11) e apresenta a quantidade identificada de quilombos espalhados por todo Brasil com uma 
breve explicação do que são e das lutas pela existência e titulação desses territórios, como exposto pelo boxe Estação Cidadania na figura 12 a seguir com o exemplo do território quilombola em Alcântara, Maranhão.

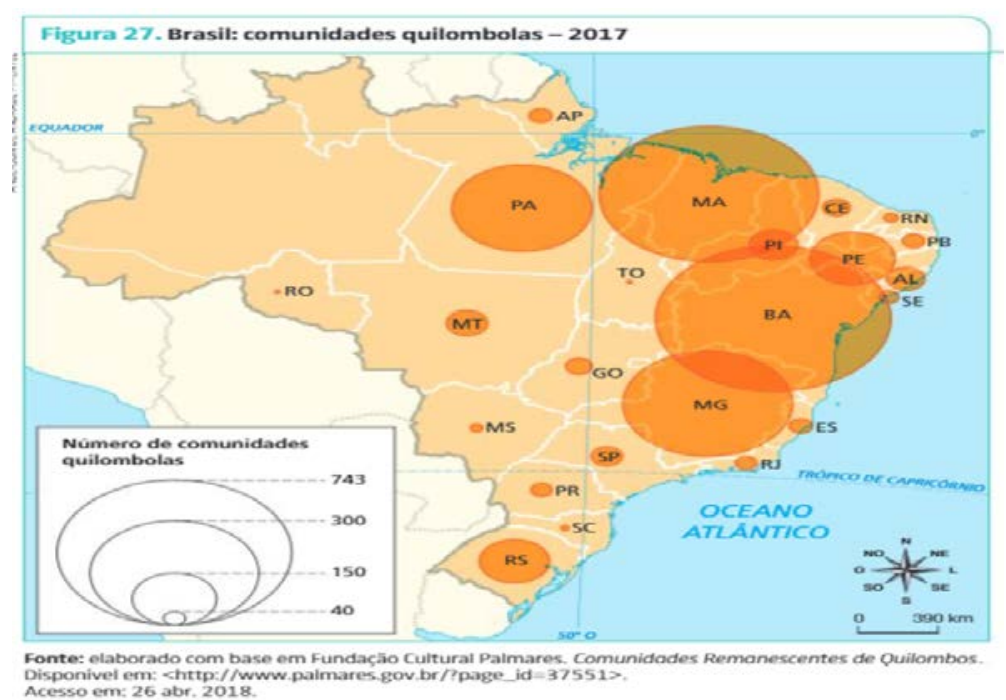

Figura 11. Mapa do número de comunidades quilombolas existentes nos municípios brasileiros no livro didático Expedições Geográficas 7º ano Fonte: Editora Moderna, 2018.

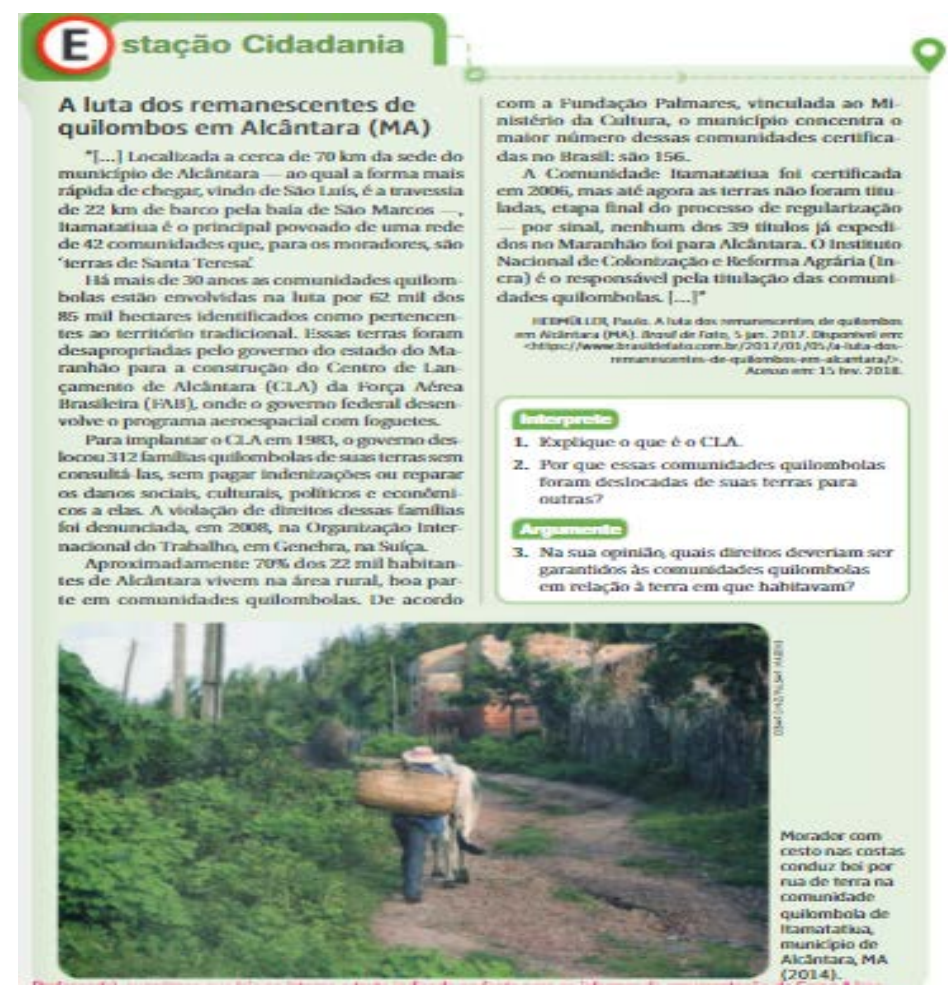

Figura 12. Estação Cidadania sobre a luta dos quilombolas nos tempos atuais no livro didático Expedições Geográficas $7^{\circ}$ ano Fonte: Editora Moderna, 2018.

Mesmo diante do que a obra aborda sobre os quilombos e o processo de resistência da população, ressalta-se a invisibilidade que o livro faz dos territórios quilombolas na 
dinâmica territorial do país e o quanto isso tende a reproduzir o discurso dominante que apaga qualquer resquício da matriz africana no Brasil e sua influência na construção da identidade nacional.

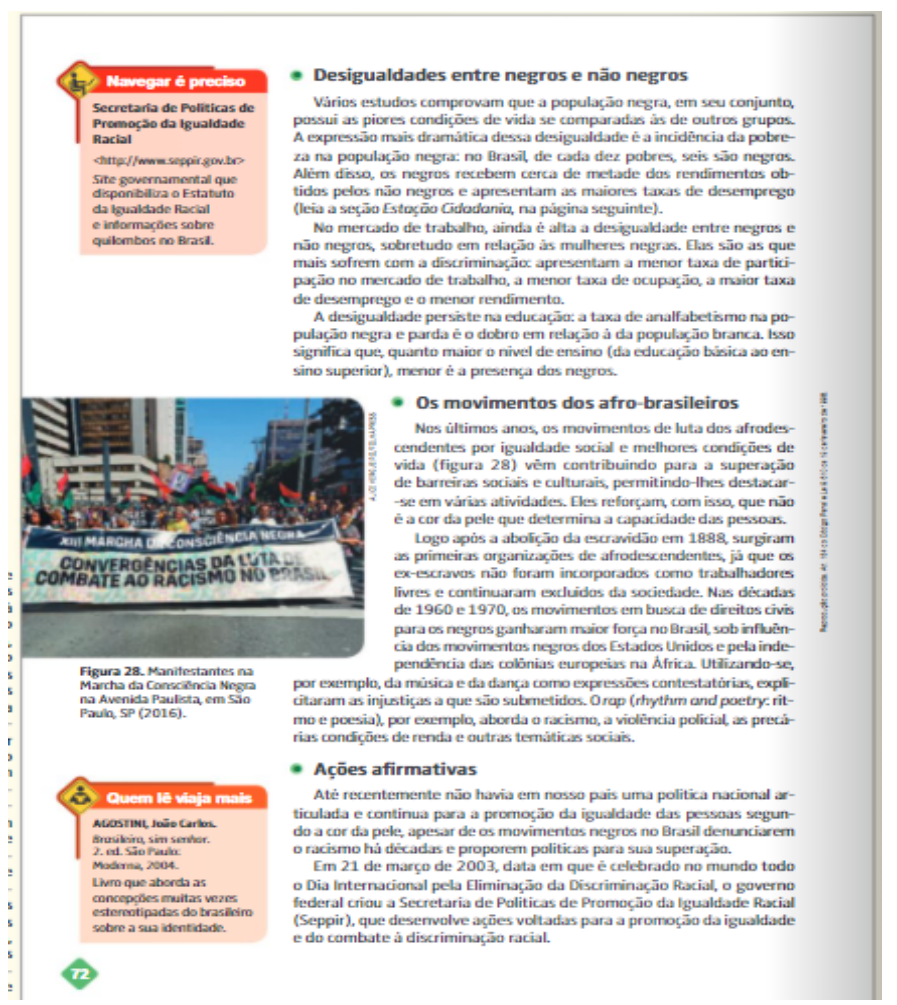

Figura 13. Página sobre população afro-brasileira no livro didático Expedições Geográficas $7^{\circ}$ ano Fonte: Editora Moderna, 2018.

Por fim, ainda no capítulo 8 é dado uma breve explicação sobre os movimentos dos afro-brasileiros na luta por igualdade e direitos (ver figura 13), contudo o tema não é aprofundado nas raízes do problema e não mostra um panorama atual dos movimentos dos desafios enfrentados pela violência institucionalizada, mas também as conquistas como as cotas nas universidades e nos concursos públicos, a representatividade na política, da própria Lei 10.639/2003, etc.

E para finalizar o mesmo capítulo apresenta um infográfico (ver figura 14) que trata sobre o racismo, a intolerância religiosa, a LGBTfobia, entre outros tipos de preconceitos enfrentados principalmente pelas crianças pretas nos espaços escolares e na internet, com a exposição de alguns dados seguido de uma proposta de reflexão sobre o assunto a partir de algumas perguntas orientadoras. 

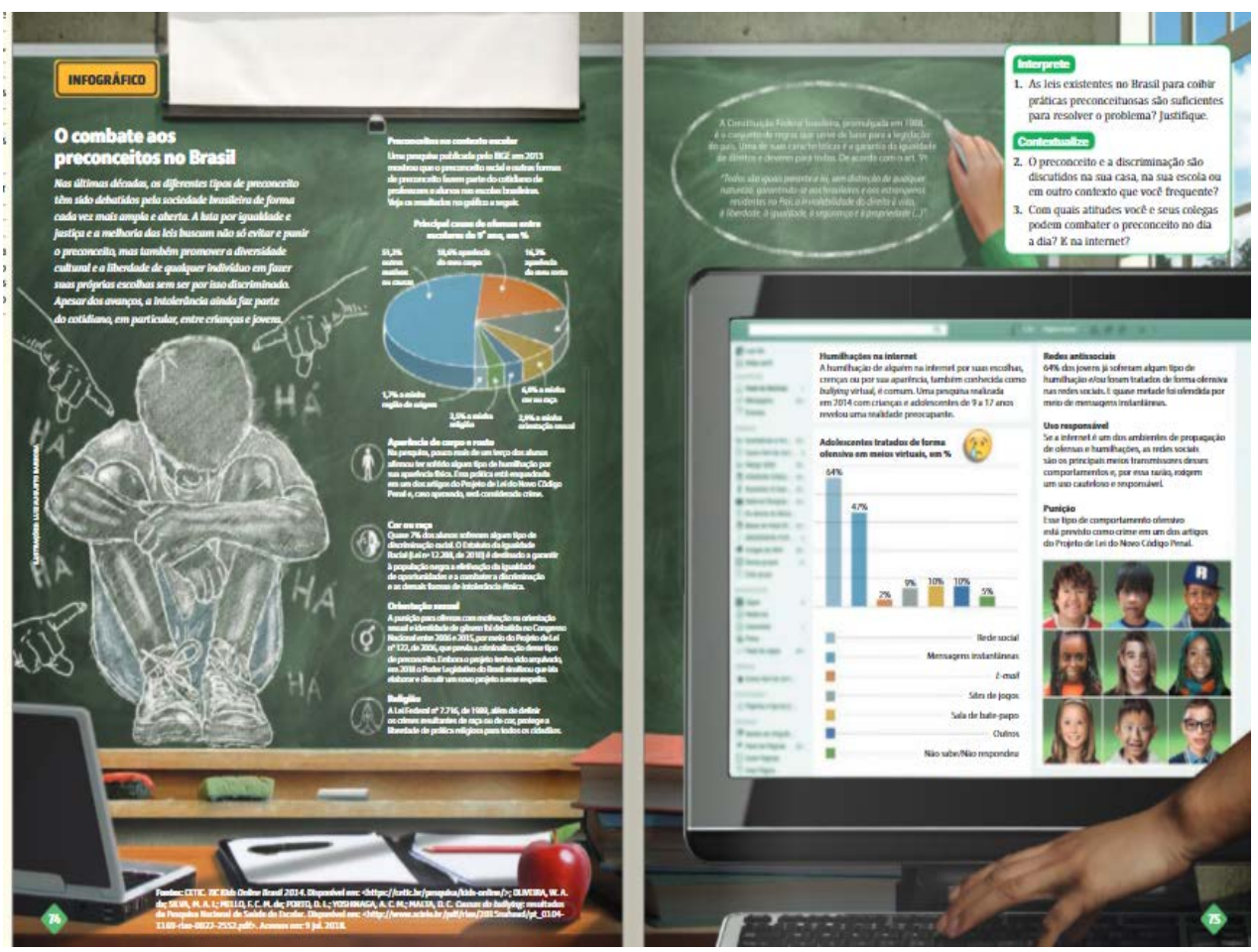

Figura 14. Infográfico sobre racismo e preconceitos enfrentados por pessoas pretas no Brasil no livro didático Expedições Geográficas $7^{\circ}$ ano Fonte: Editora Moderna, 2018.

Contudo, é importante pontuar que os livros didáticos podem optar por outras representações para além do racismo, preconceitos ou as desigualdades socioeconômicas, não desconsiderando as vulnerabilidades enfrentadas pela população afro-brasileira, mas apresentar informações positivas e não reforçar o lugar estigmatizado dos afro-brasileiros na sociedade, principalmente, em um capítulo que é intitulado como afro-brasileiros e a diversidade cultural.

\section{EXISTE ALGUMA EXPLICAÇÃO NO LIVRO PORQUE OS DESCENDENTES DO CONTINENTE AFRICANO NO BRASIL POSSUEM POSIÇÃO DESIGUAL NAS QUESTÕES LIGADAS AO TRABALHO, SAÚDE, EMPREGO E EDUCAÇÃO, PRINCIPALMENTE?}

Em apenas um capítulo tratado sobre as questões relacionadas às desigualdades socioeconômicas da população afro-brasileira em comparação com a população não negra. Especialmente ao que se trata das desigualdades são elencadas informações do senso comum e superficiais, sem embasamento teórico ou que se esforce a correlacionar com conteúdo anteriormente trabalhados e tentar promover uma reflexão crítica e sistemática do problema. 
De maneira geral quando se aborda, por exemplo, as desigualdades entre pretos e não pretos, principalmente de renda, o início do texto dar-se da seguinte forma: "Historicamente pretos e pardos apresentem indicadores sociais desfavoráveis quando comparados à população de cor branca”, outro exemplo do uso vago é: "Vários estudos comprovam que a população negra possui piores condições de vida comparados aos de outros grupos (Adas e Adas, 2018), o uso dos termos, principalmente do "historicamente" sem uma reflexão crítica remete à uma quase uma naturalização da desigualdade social presente no país.

Portanto, a obra não estabelece uma discussão sistemática sobre as causas e os porquês da pobreza da população preta no Brasil. Os dados e informações não questionam a dimensão étnica-racial da pobreza, além do uso de uma linguagem generalista e a falta de informações concretas e críticas demonstram uma negligência social e educacional com os estudantes e no combate às mazelas apresentadas no próprio texto.

\section{FINALMENTE, O LIVRO DIDÁTICO CONSIDERA AS MATRIZES ORIUNDAS DA ÁFRICA COMO VERDADEIRAS REFERÊNCIAS DA FORMAÇÃO DA SOCIEDADE BRASILEIRA? FAÇA UMA AVALIAÇÃO FINAL DO QUE PRECISA SER AJUSTADO NA PUBLICAÇÃO E O QUE PODE SER USADO NO PROCESSO EDUCACIONAL REFERENTE AO "BRASIL AFRICANO CONTEMPORÂNEO”.}

O livro “Expedições Geográficas $7^{\circ}$ ano” da Editora Moderna de forma geral não trabalha de forma satisfatória as matrizes oriundas da África como referências na formação do território e da população brasileira e quando se propõe em abordar o assunto é de forma superficial, com informações do senso comum, desconexas e sem diálogo com outros assuntos do livro que são determinantes para o entendimento do assunto levantado.

O que vimos ao longo da análise do livro é um apagamento e a promoção da invisibilidade da influência da matriz africana na dinâmica socioespacial e econômica do país. É ignorado que as mulheres e os homens afro-brasileiros são sujeitos de transformação do espaço geográfico e, portanto, construtores de espacialidades, territórios e territorialidades, paisagens e lugares marcados por culturas ancestrais (Martins e Pureza, 2020).

Ao longo de 8 unidades e 32 capítulos apenas um capítulo trata e elenca a presença da matriz africana no Brasil, justamente no qual se trata sobre o processo de 
formação da população brasileira e seus grupos e, logo não abordar os afro-brasileiros e sua ancestralidade africana seria amoral e racista.

Dessa forma, o livro não se propõe à transversalidade implementada pela Lei 10.639/2003 e com seu único capítulo referente ao tema a abordagem pode ser encarada de maneira exótica e como uma maneira de mostrar que a lei está sendo cumprida.

São inúmeros os conteúdos que se fazem necessários a serem tratados a partir da matriz africana ou pelo menos serem citados, como por exemplo ao se falar sobre o mercado de trabalho e suas nuances de desigualdade no Brasil não é levantada a reflexão da disparidade de salários, cargos, escolaridade entre trabalhadores brancos e pretos e muito menos as raízes históricas desse problema; outro ponto é ao tratar sobre o fluxo migratório no território brasileiro os únicos grupos populacionais citados são os europeus e asiáticos; já no estudo sobre a regiões brasileiras e a construção dos seus espaços geográficos não é mencionada a presença dos africanos e dos afro-brasileiros, até mesmo quando se fala sobre os aspectos culturais da região não é feita a menção sobre as influências de matriz africana.

Em uma análise final, podemos apontar que o livro não é satisfatório quanto ao processo educacional referente ao "Brasil Africano" contemporâneo, visto a falta de aprofundamento e de conexão com outras temáticas pertinentes no desenvolvimento das questões que envolvem as relações étnico-raciais no Brasil.

De modo geral as questões étnico-raciais e o Brasil Africano são erroneamente tratadas nos livros didáticos pela difundida presença do mito da democracia racial no imaginário social brasileiro, além da reprodução hegemônica do pensamento eurocêntrico e branco que permeia as ciências e as instituições e logo implicam na confecção e elaboração dos materiais didáticos e na formação dos docentes e, consequentemente, na abordagem do tema em sala de aula.

\section{Conclusão e recomendações}

A partir do analisado no livro Expedições Geográficas e levando em conta que os livros didáticos são instrumentos de papel relevante no processo de ensino-aprendizagem e, portanto carecem de atenção, cuidado e criticidade em sua formulação, independente da didática e ensinagem dos professores o livro didático é um importante aliado e pode 
direcionar a condução dos conteúdos trabalhados e das reflexões colocadas em discussão nas salas de aula e podem ser as únicas fontes de consulta, leitura e estudo dos estudantes.

Com isso, aponta-se para a necessidade de uma abordagem transversal do "Brasil Africano” no livro como indica a Lei 10.639/2003 e propor a desmitificação do exotismo do tema apenas ao que se refere à diversidade cultural e à miscigenação.

Além disso, é importante ressaltar que a resolução dos problemas não se restringe a inserção dos novos conteúdos ou a abordagem transversal, mas deve ser feita a revisão dos conteúdos que outrora foram estabelecidos e que são incompatíveis com os novos paradigmas estipulados em leis. Logo, alguns temas e assuntos precisam ser inseridos e outros revistos ou readequados a nova conjuntura (Marcelino, 2020).

Dessa forma, não é apenas cumprir a Base Nacional Curricular Comum (BNCC) ou que é imposta pela Lei 10.639/2003, mas trazer o assunto como forma de promover o conhecimento da história, do resgate à ancestralidade, da valorização das raízes brasileiras, de relações étnico-raciais respeitosas dentro e fora do contexto escolar e combater o racismo, preconceitos e a violência institucional e assim formar cidadãos críticos.

\section{Referências Bibliográficas}

ADAS, M; ADAS, S. Expedições Geográficas: manual do professor. $3^{\mathrm{a}}$ ed. São Paulo: Moderna, 2018.

MARCELINO, J. S. Geografia da África: Possibilidades para uma Educação Antirracista. Abatirá - Revista de Ciência Humanas e Linguagens, Eunápolis, v. 1, n. 1, p. 118-145, 2020.

MARTINS, A. B.; PUREZA, M. G. B. O ensino de geografia e as relações étnico-raciais nos livros didáticos no ensino fundamental. Revista Geografia Ensino e Pesquisa, Santa Maria, v. 24, n. 18, 2020.

RATTS, A. J. P. et al. Representações da África e da população negra nos livros didáticos de geografia. Revista da Casa de Geografia de Sobral, Sobral, v. 8/9, n. 1, p. 45-59, 2006/2007. 
ROCHA, H. S. C. O que sabe quem ensina África na Geografia? Impactos na implementação da Lei no 10.639 no IFPA-campus Belém. Revista Thema, v. 8, n. 2, 2011.

SANTOS, M. O espaço geográfico como categoria filosófica. Terra Livre, $\mathrm{n}^{\circ}$ 05. São Paulo: AGB, 1988. 